\title{
Predominancia del discurso de distribución de competencias en la legislación orgánica de ordenamiento territorial de Colombia: una aproximación al enfoque administrativo imperante
}

María Luisa Monroy Merchán

Oficina Asesora de Planeación de la Secretaria Distrital de Movilidad de Bogotá, Colômbia

Recebido: 19/07/2013 Versão revisada (entregue): 29/11/2013 Aprovado: 03/12/2013

\begin{abstract}
Resumen
El propósito de este artículo es analizar la Ley Orgánica de Ordenamiento Territorial, considerándola a partir de una lógica presupuestaria y de la distribución de competencias y no como una ley de reorganización territorial que favorezca la autonomía de las organizaciones estaduales y municipales. Para lograr este propósito, se examina el marco legal del ordenamiento territorial de Colombia, fundamentalmente, la Carta Política de 1991 y los artículos relacionados con la formación de entidades territoriales. También se examinan las disposiciones que tratan de las competencias entre la nación, los estados y los municipios, que definen la distribución de los recursos entre los órganos de administración de estos niveles de gobierno y los indicadores de rendimiento de integración municipal con los que se mensura el comportamiento fiscal y administrativo de las entidades territoriales. La evidencia indica que hay poco interés político en la ampliación del debate acerca de la organización territorial de Colombia dado que el mapa político-electoral del país podría cambiar, afectando la vigente distribución de recursos presupuestarios. De ello se desprende que la Ley Orgánica de Ordenamiento Territorial es tímida, limitándose a la cuestión de las competencias.
\end{abstract}

Palabras-clave | Autonomía regional; Colombia; distribución de competencias; gastos públicos; entidades territoriales; Ley Orgánica de Ordenamiento Territorial.

Código JEL | O18; O21; R52. 


\title{
PREDOMÍNIO DO DISCURSO DE DISTRIBUIÇÃO DE COMPETÊNCIAS NA LEGISLAÇÃO ORGÂNICA DE ORDENAMENTO TERRITORIAL DA COLÔMBIA: UMA APROXIMAÇÃO AO ENFOQUE ADMINISTRATIVO DOMINANTE
}

\section{Resumo}

O objetivo neste artigo é analisar a Lei Orgânica de Ordenamento Territorial, que tem sido considerada a partir de uma lógica orçamentária e de distribuição de competências e não como uma lei da reorganização territorial que favoreça a autonomia das organizações estaduais e municipais. Para a consecução deste intento, examina-se o marco jurídico do ordenamento territorial da Colômbia, fundamentalmente, a Carta Política de 1991 e os artigos relacionados com a formação de entidades territoriais, assim como as normas que tratam das competências entre a nação, os estados e os municípios, as quais definem a distribuição dos recursos entre os órgãos administrativos desses níveis de governo, e os indicadores de desempenho de integração municipal, com os quais é mensurado o comportamento fiscal e administrativo das entidades territoriais. As evidências indicam haver reduzido interesse político em se ampliar o debate sobre a organização territorial da Colômbia, posto que o mapa político-eleitoral do país poderia ser alterado, afetando a distribuição de recursos orçamentários vigente. Daí se conclui que a Lei Orgânica de Ordenamento Territorial é tímida, restringindo-se ao tema das competências.

Palavras-chave | Autonomia regional; distribuição de competências; gastos públicos; entidades territoriais; Lei Orgânica de Ordenamento Territorial.

Código JEL | O18; O21; R52.

\section{THE PREDOMINANCE OF THE DISCOURSE OF COMPETENCES DISTRIBUTION IN THE ORGANIC LEGISLATION ON TERRITORIAL ORDINANCE OF COLOMBIA: AN APPROXIMATION TO THE DOMINANT ADMINISTRATIVE APPROACH}

\begin{abstract}
The purpose in this article is to analyze the Organic Law of Territorial Ordinance, which has been considered from the logic of budget and of power distribution, but not as a law of territorial reorganization which could favor the autonomy of state and local organizations. In order to achieve this purpose, the legal framework of territorial ordinance in Colombia, fundamentally, the Political Chart of 1991, and the articles related to the formation of territorial entities are examined. Likewise the legal norms that address the competences among the nation, the states and municipalities, which define the distribution of resources among the administrative bodies of these levels of government, as well as the performance indicators for municipal integration, which measured the fiscal and administrative behavior of territorial entities are here considered. The evidences indicate that there is low political interest in broadening the debate on territorial organization of Colombia, since the political and electoral map of the country could be changed, affecting the distribution of existing budgetary resources. It follows that the Organic Law on Territorial Organization is timid, limited to the issue of competences.
\end{abstract}

Keywords | Regional autonomy; competences distribution; public spending; territorial entities; Organic Law for Territorial Ordinance.

JEL-Code | O18; O21; R52. 


\section{Introducción}

El presente artículo tiene como objetivo identificar el enfoque que ha asumido el gobierno colombiano frente al tema relacionado con la legislación orgánica de ordenamiento territorial, tema que dada sus connotaciones políticas es asumido bajo la lógica presupuestaria y de distribución de competencias entre entidades territoriales, lo que no ha permitido una discusión profunda que resuelva de forma estructural la organización territorial colombiana y con ello la administración y manejo de los recursos físicos, humanos y fiscales del país.

\section{La Constitución Política de 1991 y el ordenamiento territorial de Colombia}

La Constitución Política de 1991 establece que la organización territorial del país se define mediante una ley orgánica. Sin embargo, después de más de dos décadas, el país no ha logrado determinar un aspecto esencial para la administración de su territorio y de sus recursos.

Partiendo del principio fundamental que consagra la carta política, "Colombia es un Estado social de derecho, organizado en forma de República unitaria, descentralizada, con autonomía de sus entidades territoriales, democrática, participativa y pluralista [...]", es evidente que la fórmula para lograr canalizar y aglutinar las demandas ciudadanas de descentralización política y administrativa de los recursos fue establecer como principio una organización que no fuera lo suficientemente federalista ni altamente centralista, sino que conjugara el control de los recursos desde su capital, Bogotá, y abriera los escenarios de participación política de las regiones; fórmula, que poco le ha permitido al país avanzar en su organización territorial y con ello lograr un desarrollo regional.

En este sentido, en varios de los artículos de la Constitución Política se aplaza el debate de la organización territorial, postergando su definición a una Ley de carácter orgánica que implica para su aprobación la mayoría absoluta de los miembros de una y otra Cámara, mientras que la ley ordinaria es aprobada por la mayoría simple de los asistentes. Una ley orgánica "es de naturaleza jerárquica superior a las demás leyes que versen sobre el mismo contenido material, ya que éstas deben ajustarse a lo que organiza aquella. Pero, propiamente hablando, la ley orgánica no tiene el rango de norma constitucional, porque no está constituyendo sino organizando lo ya constituido por la norma de normas, que es, únicamente, el Estatuto Fundamental. La ley orgánica no es el primer fundamento jurídico, sino una pauta a seguir en determinadas materias preestablecidas, no por ella misma, sino por la Constitución." (Sentencia C-701/10 Magistrado Ponente Dr. Luis Ernesto Vargas Silva, subrayada y cursiva fuera de texto original). 
Los artículos que le atribuyen la calidad de reglamentación orgánica al tema del ordenamiento territorial se desglosan en el siguiente cuadro:

\section{Cuadro 1 - Artículos de la Constitución Política de 1991 relacionados con ordenamiento territorial}

\begin{tabular}{|c|c|c|}
\hline $\begin{array}{c}\mathbf{N}^{\circ} \text { del } \\
\text { Articulo }\end{array}$ & Reseña & $\begin{array}{l}\text { Principal } \\
\text { Atributo }\end{array}$ \\
\hline $\begin{array}{l}\text { Articulo } \\
288\end{array}$ & $\begin{array}{l}\text { La ley orgánica de ordenamiento territorial establecerá la } \\
\text { distribución de competencias entre la Nación y las entidades } \\
\text { territoriales. Las competencias atribuidas a los distintos niveles } \\
\text { territoriales serán ejercidas conforme a los principios de } \\
\text { coordinación, concurrencia y subsidiariedad en los términos que } \\
\text { establezca la ley. }\end{array}$ & $\begin{array}{l}\text { Competencias y } \\
\text { Principio entre } \\
\text { la Nación y las } \\
\text { entidades } \\
\text { territoriales. }\end{array}$ \\
\hline $\begin{array}{l}\text { Artículo } \\
297\end{array}$ & $\begin{array}{l}\text { El Congreso Nacional puede decretar la formación de nuevos } \\
\text { Departamentos, siempre que se cumplan los requisitos exigidos } \\
\text { en la Ley Orgánica del Ordenamiento Territorial y una vez } \\
\text { verificados los procedimientos, estudios y consulta popular } \\
\text { dispuestos por esta Constitución. }\end{array}$ & $\begin{array}{l}\text { Formación de } \\
\text { Nuevos } \\
\text { Departamentos. }\end{array}$ \\
\hline $\begin{array}{l}\text { Artículo } \\
307\end{array}$ & $\begin{array}{l}\text { La respectiva ley orgánica, previo concepto de la Comisión de } \\
\text { Ordenamiento Territorial, establecerá las condiciones para } \\
\text { solicitar la conversión de la región en entidad territorial. La } \\
\text { decisión tomada por el Congreso se someterá en cada caso a } \\
\text { referendo de los ciudadanos de los departamentos interesados. } \\
\text { La misma ley establecerá las atribuciones, los órganos de } \\
\text { administración, y los recursos de las regiones y su participación } \\
\text { en el manejo de los ingresos provenientes del Fondo } \\
\text { Nacional de Regalías. Igualmente definirá los principios para la } \\
\text { adopción del estatuto especial de cada región. }\end{array}$ & $\begin{array}{l}\text { Formación de } \\
\text { Regiones y } \\
\text { órganos de } \\
\text { administración } \\
\text { de las mismas. }\end{array}$ \\
\hline $\begin{array}{l}\text { Articulo } \\
319\end{array}$ & $\begin{array}{l}\text { Cuando dos o más municipios tengan relaciones económicas, } \\
\text { sociales y físicas, que den al conjunto características de un área } \\
\text { metropolitana, podrán organizarse como entidad administrativa } \\
\text { encargada de programar y coordinar el desarrollo armónico e } \\
\text { integrado del territorio colocado bajo su autoridad; racionalizar la } \\
\text { prestación de los servicios públicos a cargo de quienes la integran } \\
\text { y, si es el caso, prestar en común algunos de ellos; y ejecutar } \\
\text { obras de interés metropolitano. La ley de ordenamiento } \\
\text { territorial adoptará para las áreas metropolitanas un régimen } \\
\text { administrativo y fiscal de carácter especial; garantizará que en sus } \\
\text { órganos de administración tengan adecuada participación las } \\
\text { respectivas autoridades municipales; y señalará la forma de } \\
\text { convocar y realizar las consultas populares que decidan la } \\
\text { vinculación de los municipios. Cumplida la consulta popular, los } \\
\text { respectivos alcaldes y los concejos municipales protocolizarán la } \\
\text { conformación del área y definirán sus atribuciones, financiación } \\
\text { y autoridades, de acuerdo con la ley. }\end{array}$ & $\begin{array}{l}\text { Formación de } \\
\text { Áreas } \\
\text { Metropolitanas } \\
\text { y organización } \\
\text { administrativa } \\
\text { del mismo. }\end{array}$ \\
\hline
\end{tabular}




\begin{tabular}{|l|l|l|}
\hline $\begin{array}{c}\text { No del } \\
\text { Articulo }\end{array}$ & \multicolumn{1}{|c|}{ Reseña } & \multicolumn{1}{|c|}{$\begin{array}{c}\text { Principal } \\
\text { Atributo }\end{array}$} \\
\hline \multirow{3}{*}{$\mathbf{3 2 9}$} & $\begin{array}{l}\text { La conformación de las entidades territoriales indígenas se hará } \\
\text { con sujeción a lo dispuesto en la Ley Orgánica de Ordenamiento } \\
\text { Territorial, y su delimitación se hará por el Gobierno Nacional, } \\
\text { con participación de los representantes de las comunidades } \\
\text { indígenas, previo concepto de la Comisión de Ordenamiento } \\
\text { Territorial. } \\
\text { Los resguardos son de propiedad colectiva y no enajenable. } \\
\text { Ea ley definirá las relaciones y la coordinación de estas entidades } \\
\text { territoriales } \\
\text { indígenas. }\end{array}$ \\
& $\begin{array}{l}\text { Lan aquellas de las cuales formen parte. } \\
\text { carágrafo. En el caso de un territorio indígena que comprenda el } \\
\text { territorio de dos o más departamentos, su administración se hará } \\
\text { por los consejos indígenas en coordinación con los gobernadores } \\
\text { de los respectivos departamentos. En caso de que este territorio } \\
\text { decida constituirse como entidad territorial, se hará con el } \\
\text { cumplimiento de los requisitos establecidos en el inciso primero } \\
\text { de este artículo. }\end{array}$ & \\
\hline
\end{tabular}

Como se observa del anterior cuadro, son dos grandes temas que previo la Constituyente se reglamentarían mediante la ley orgánica de ordenamiento territorial: primero, la distribución de competencias entre la nación y las entidades territoriales; y segundo, la conformación y organización administrativa de nuevas entidades territoriales, como lo son: los departamentos, las áreas metropolitanas y las entidades territoriales indígenas.

Frente al primero aspecto, vale subrayar que el Legislador ha dispuesto una serie de normatividades que permiten vislumbrar el Principio fundamental de la Organización Territorial Colombiana, es decir "la autonomía regional subordinada al manejo fiscal centralista".

Si bien la distribución de competencias se debían determinar mediante ley orgánica, el legislador permitió su avance normativo en virtud del principio de conexidad temática; es así como la Corte Constitucional precisó "La Constitución no probibe que una misma ley contenga materias orgánicas y temas de la ley ordinaria, siempre y cuando éstos guarden una conexidad temática razonable." (Sentencia C-600-A/95, diciembre 11. Corte Constitucional. Magistrado Ponente doctor Alejandro Martínez Caballero). Y así mismo admitió que si bien se exigía que una ley orgánica reglamentara las materias del ordenamiento territorial, era posible la expedición de varias leyes por cuanto considera la Corte que "en aras de la seguridad jurídica y la coherencia del ordenamiento jurídico, es recomendable que esta materia se sistematice en una sola ley. Sin embargo, la Constitución no exige esa formalidad, por lo cual precisamente esta sentencia ha preferido hablar de "legislación orgánica de ordenamiento territorial." (Sentencia C-600-A/95, diciembre 11). 
En este sentido, el legislador encauzó la reglamentación en la distribución de las competencias entre la Nación y las entidades territoriales amparado en: primero, el principio de conexidad temática entre leyes, segundo; la posibilidad de emitir varias normatividades, en tanto la Carta Política no es restrictiva en la forma de su expedición y tercero la derivación de normatividades sin acudir a una ley orgánica que sirviera de referente, puesto que la Constitución enuncia los principios generales de la distribución de competencias; tal como lo señala la Corte "en algunos casos la propia Constitución distribuye ella misma ciertas competencias, de suerte que una ley ordinaria puede desarrollar el tema con base en las prescripciones generales de la Carta." (Sentencia C-600-A/95, diciembre 11).

Contando con el camino despejado, el legislador emitió las siguientes normatividades en materia de distribución de competencias:

Cuadro 2 - Normatividades en materia de distribución de competencia

\begin{tabular}{|c|c|c|c|c|}
\hline Ley & $\begin{array}{c}\text { Tema que } \\
\text { Reglamenta }\end{array}$ & $\begin{array}{l}\text { Identificación } \\
\text { de la Ley }\end{array}$ & $\begin{array}{c}\text { Marco de } \\
\text { Referencia en la } \\
\text { Constitución } \\
\text { Política }\end{array}$ & $\begin{array}{c}\text { Temas de } \\
\text { Competencias } \\
\text { que resuelve la } \\
\text { Ley }\end{array}$ \\
\hline $\begin{array}{l}\text { Decreto } 111 \text { de } \\
\mathbf{1 9 9 6} \\
\text { Por el cual se } \\
\text { compilan la Ley } \\
38 \text { de 1989, la } \\
\text { Ley } 179 \text { de } 1994 \\
\text { y la Ley } 225 \text { de } \\
1995 \\
\text { conforman que } \\
\text { Estatuto } \\
\text { Orgánico } \\
\text { Presupuesto. }\end{array}$ & $\begin{array}{l}\text { Programación, } \\
\text { elaboración, } \\
\text { presentación, } \\
\text { aprobación, } \\
\text { modificación y } \\
\text { ejecución del } \\
\text { presupuesto. }\end{array}$ & $\begin{array}{l}\text { Ley Orgánica } \\
\text { Estatuto } \\
\text { Orgánico del } \\
\text { Presupuesto } \\
\text { General de la } \\
\text { Nación. }\end{array}$ & $\begin{array}{l}\text { Capítulo III Del } \\
\text { Presupuesto } \\
\text { Artículo 352. } \\
\text { La ley Orgánica del } \\
\text { Presupuesto regulará } \\
\text { lo correspondiente a } \\
\text { la programación, } \\
\text { aprobación, } \\
\text { modificación, } \\
\text { ejecución de los } \\
\text { presupuestos de la } \\
\text { Nación, de las } \\
\text { entidades } \\
\text { territoriales y de los } \\
\text { entes de } \\
\text { descentralizados de } \\
\text { cualquier nivel } \\
\text { administrativo, y su } \\
\text { coordinación con el } \\
\text { Plan Nacional de } \\
\text { Desarrollo, así como } \\
\text { también la capacidad } \\
\text { de los organismos y } \\
\text { entidades estatales } \\
\text { para contratar. }\end{array}$ & $\begin{array}{lr}\text { - Banco } & \\
\text { Nacional } & \text { de } \\
\text { Programas } & \text { y } \\
\text { Proyectos. } & \\
\text { - Préstamos a las } \\
\text { entidades } \\
\text { territoriales } & \text { de la } \\
\text { República. } & \\
\text { - Adopción } & \text { de } \\
\text { las disposiciones } \\
\text { de la r Ley } \\
\text { Orgánica r por } \\
\text { parte de r las } \\
\text { entidades r } \\
\text { territoriales. }\end{array}$ \\
\hline
\end{tabular}




\begin{tabular}{|c|c|c|c|c|}
\hline Ley & $\begin{array}{c}\text { Tema que } \\
\text { Reglamenta }\end{array}$ & $\begin{array}{l}\text { Identificación } \\
\text { de la Ley }\end{array}$ & $\begin{array}{c}\text { Marco de } \\
\text { Referencia en la } \\
\text { Constitución } \\
\text { Política }\end{array}$ & $\begin{array}{c}\text { Temas de } \\
\text { Competencias } \\
\text { que resuelve la } \\
\text { Ley }\end{array}$ \\
\hline 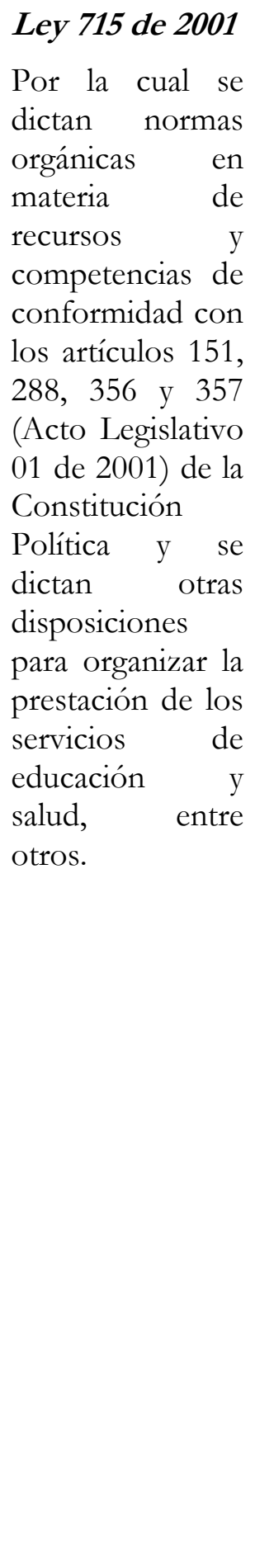 & $\begin{array}{l}\text { Conformación } \\
\text { del Sistema } \\
\text { General de } \\
\text { Participaciones: } \\
\text { sector } \\
\text { educativo, } \\
\text { sector salud, } \\
\text { propósito } \\
\text { general que } \\
\text { incluye los } \\
\text { recursos para } \\
\text { agua potable y } \\
\text { saneamiento } \\
\text { básico. }\end{array}$ & Ley Orgánica. & 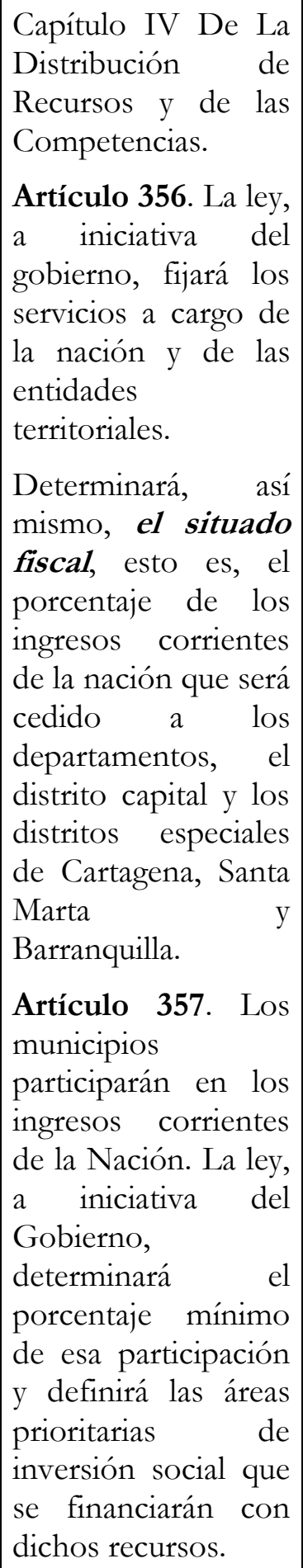 & $\begin{array}{l}\text { - Naturaleza del } \\
\text { Sistema General } \\
\text { de } \\
\text { Participaciones. } \\
\text { - Competencias } \\
\text { de la Nación en } \\
\text { materia de } \\
\text { educación, salud. } \\
\text { - Competencias } \\
\text { de los } \\
\text { departamentos } \\
\text { en materia de } \\
\text { educación, salud. } \\
\text { - Competencias } \\
\text { de los distritos y } \\
\text { los municipios } \\
\text { certificados en } \\
\text { educación. } \\
\text { - Competencias } \\
\text { en salud por } \\
\text { parte de los } \\
\text { Distritos. } \\
\text { - Competencias } \\
\text { de la Nación en } \\
\text { otros sectores. } \\
\text { - Competencia } \\
\text { de los } \\
\text { Departamentos } \\
\text { en otros } \\
\text { sectores. } \\
\text { - Distribución y } \\
\text { administración } \\
\text { de los recursos } \\
\text { para resguardos } \\
\text { indígenas. }\end{array}$ \\
\hline
\end{tabular}




\begin{tabular}{|c|c|c|c|c|}
\hline Ley & $\begin{array}{c}\text { Tema que } \\
\text { Reglamenta }\end{array}$ & $\begin{array}{c}\text { Identificación } \\
\text { de la Ley }\end{array}$ & $\begin{array}{c}\text { Marco de } \\
\text { Referencia en la } \\
\text { Constitución } \\
\text { Política }\end{array}$ & $\begin{array}{c}\text { Temas de } \\
\text { Competencias } \\
\text { que resuelve la } \\
\text { Ley } \\
\end{array}$ \\
\hline $\begin{array}{l}\text { Ley } 819 \text { de } 2003 \\
\text { Por la cual se } \\
\text { dictan normas } \\
\text { orgánicas en } \\
\text { materia } \\
\text { presupuesto, de } \\
\text { responsabilidad y } \\
\text { transparencia } \\
\text { fiscal y se dictan } \\
\text { otras } \\
\text { disposiciones. }\end{array}$ & 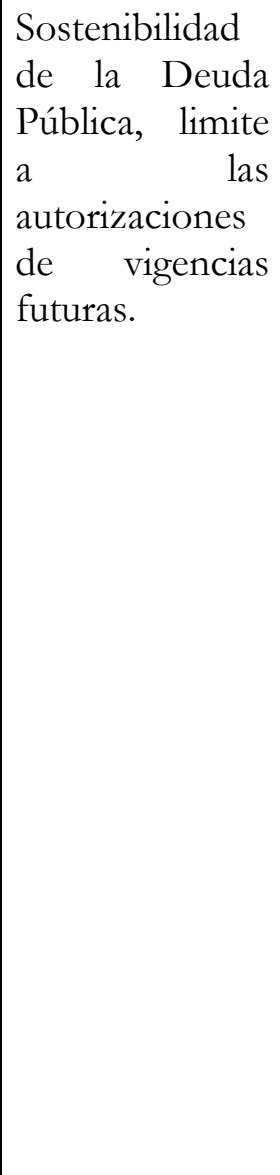 & Ley Orgánica. & $\begin{array}{l}\text { Capítulo III Del } \\
\text { Presupuesto } \\
\text { Artículo 352. La ley } \\
\text { Orgánica del } \\
\text { Presupuesto regulará } \\
\text { lo correspondiente a } \\
\text { la programación, } \\
\text { aprobación, } \\
\text { modificación, } \\
\text { ejecución de los } \\
\text { presupuestos de la } \\
\text { Nación, de las } \\
\text { entidades } \\
\text { territoriales y de los } \\
\text { entes } \\
\text { descentralizados de } \\
\text { cualquier nivel } \\
\text { administrativo, y su } \\
\text { coordinación con el } \\
\text { Plan Nacional de } \\
\text { Desarrollo, así como } \\
\text { también la capacidad } \\
\text { de los organismos y } \\
\text { entidades estatales } \\
\text { para contratar. }\end{array}$ & $\begin{array}{l}\text { - Disciplina } \\
\text { Fiscal. } \\
\text { - Endeudamient } \\
\text { o Territorial. } \\
\text { - Montor y } \\
\text { utilización de } \\
\text { Recursos } \\
\text { Públicos. }\end{array}$ \\
\hline
\end{tabular}

Como se observa en el anterior cuadro, la Ley 715 de 2001 es el eje rector en la definición de competencias en función a la distribución de recursos del Sistema General de Participaciones SGP, recursos que asigna la nación a las entidades territoriales, los cuales se destinan exclusivamente a salud, educación, agua potable y saneamiento básico.

El modelo de cascada de distribución de competencias entre la nación, los departamentos y los municipios para la distribución de los recursos del Sistema General de Participaciones, tomando como ejemplo, el sector educativo, funciona de la siguiente manera:

La Nación realiza la formulación y regulación de las políticas del sector educativo, la evaluación de la gestión financiera, técnica y administrativa y la definición del costo por alumno.

Los Departamentos, actúan de acuerdo a la condición administrativa de los municipios, la cual consiste en la capacidad que tiene la entidad territorial de 
manejar de manera "autónoma” los recursos del Sistema General de Participaciones; si el municipio cumple con esta "mayoría de edad" el departamento expide una Certificación, en la cual se reconocen la facultades administrativas para el manejo de los recursos; en este caso, el departamento solamente se encarga de prestar asistencia técnica a los municipios, quienes asumen las funciones de organización y administración de la prestación del servicio educativo, propendiendo por el aumento de la cobertura y de calidad del mismo. En caso contrario, si el municipio no cumple con la mayoría de edad, el departamento asume las funciones de los municipios certificados.

A continuación se presenta el modelo en cascada para distribución de competencias entre la Nación y las entidades territoriales, según lo establecido en la Ley 715 de 2001:

\section{Ilustración 1 - Esquema de distribución de competencias, Ley N. 715/2001}

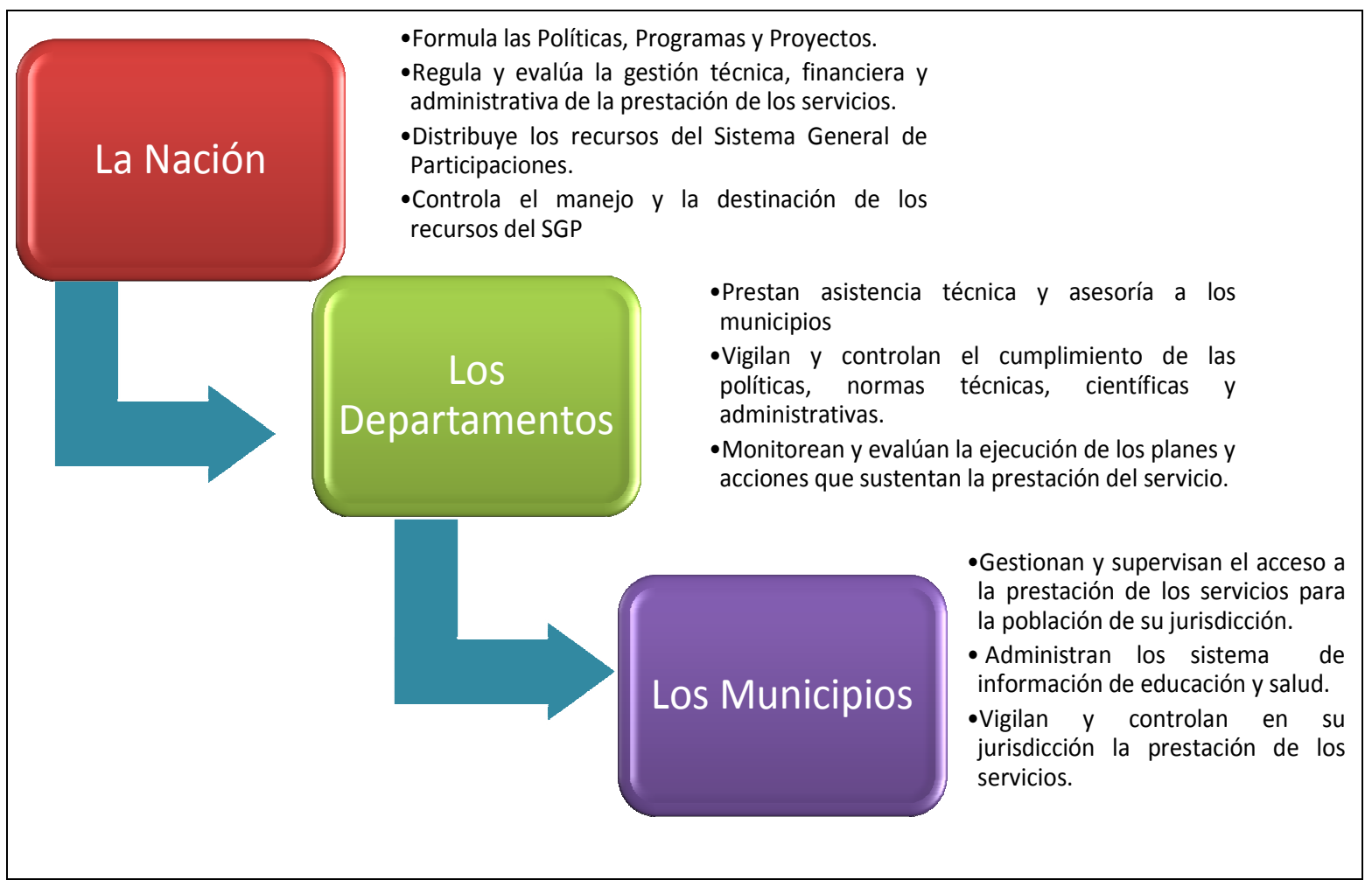

Del modelo en cascada para la distribución de las competencias surgen las siguientes inquietudes: ¿esta distribución ha sido adecuada para cerrar las brechas institucionales en la asignación de recursos? ¿El modelo de distribución han generado mayores niveles de equidad en la población?, ¿estos arreglos normativos han mejorado la gobernabilidad local y la descentralización administrativa? 


\section{Los municipios según el Indicador de Desempeño Integral Municipal}

Para responder inicialmente estas preguntas, se acude al informe realizado por el Departamento Nacional de Planeación "Evaluación del desempeño integral de los municipios-2011”, el cual, genera un instrumento de evaluación denominado indice de desempeño municipal, construido con base en los resultados que se obtienen de los municipios en los componentes de eficacia (cumplimiento del plan de desarrollo) eficiencia (comparación entre los productos generados y los recursos utilizados), gestión y cumplimiento de requisitos legales (previstos en la Ley 715); a estos componentes se les asigna una ponderación de igual peso que da como resultado el índice de desempeño municipal.

Según el informe, el indicador de desempeño integral municipal, agregado por departamentos, muestra los siguientes resultados, de acuerdo a los rangos indicados:

Cuadro 3 - Indicador de Desempeño Integral Municipal agregado por Departamentos

\begin{tabular}{|c|c|c|c|c|}
\hline Calificación & Rango & Característica & $\begin{array}{c}\mathbf{N}^{\circ} \\
\text { Departamentos }\end{array}$ & $\begin{array}{c}\mathrm{N}^{\circ} \mathrm{de} \\
\text { Municipios }\end{array}$ \\
\hline Sobresaliente & $>80$ & $\begin{array}{l}\text { Municipios que cumplen todas o } \\
\text { casi todas las metas de sus planes } \\
\text { de desarrollo, los bienes y servicios } \\
\text { son generados con alta eficiencia y } \\
\text { tienen mayor capacidad de gestión } \\
\text { administrativa y fiscal. Son los } \\
\text { municipios de mejores prácticas. }\end{array}$ & Bogotá (1) & 93 \\
\hline Satisfactoria & $\begin{array}{l}>\_70 y \\
<80\end{array}$ & $\begin{array}{l}\text { Municipios que cumplen } \\
\text { considerablemente buena parte de } \\
\text { las metas de sus planes de } \\
\text { desarrollo y la mayoría de los } \\
\text { bienes y servicios son producidos } \\
\text { con niveles aceptables de eficiencia, } \\
\text { sus finanzas son estables y han } \\
\text { alcanzado capacidades } \\
\text { administrativas importantes. }\end{array}$ & $\begin{array}{l}\text { Cundinamarca, } \\
\text { Boyacá Huila y } \\
\text { Risaralda (4) }\end{array}$ & 294 \\
\hline Medio & $\begin{array}{l}>\_60 y \\
<70\end{array}$ & $\begin{array}{l}\text { Municipios que cumplen } \\
\text { parcialmente sus planes de } \\
\text { desarrollo y la eficiencia en la } \\
\text { producción de bienes y servicios } \\
\text { están en la mitad. Además, han } \\
\text { desarrollo a medias sus capacidades } \\
\text { administrativa y fiscal. }\end{array}$ & $\begin{array}{l}\text { Atlántico, Anti- } \\
\text { oquia, Casanare, } \\
\text { Cauca, Quindío, } \\
\text { Norte de San- } \\
\text { tander, Nariño, } \\
\text { San Andrés, } \\
\text { Santander, } \\
\text { Tolima, Valle } \\
\text { del Cauca (11) }\end{array}$ & 291 \\
\hline
\end{tabular}




\begin{tabular}{|l|l|l|l|c|}
\hline Calificación & Rango & \multicolumn{1}{|c|}{ Característica } & \multicolumn{1}{|c|}{$\mathbf{N}^{\circ}$} & $\begin{array}{c}\mathbf{N}^{\circ} \text { de } \\
\text { Departamentos }\end{array}$ \\
Municipios
\end{tabular}

Fuente: DNP (2011).

Como se evidencia en el siguiente gráfico, del total de municipios del país (1101), el 30\% se encuentran en una clasificación baja, es decir cumplen una parte de los planes de desarrollo y la entrega de bienes y servicios es de carácter ineficiente. Siendo sobresaliente, solo el $8 \%$ de los municipios del país. De manera que el comportamiento en términos de gestión administrativa, fiscal, cumplimiento de los planes de desarrollo y eficiencia entre los recursos destinados y los productos entregados a la ciudadanía, oscila entre una clasificación baja y media que representa el 56\% del total de la clasificación del índice de desempeño integral municipal.

Gráfico 1 - Clasificación de los municipios según el Indicador de Desempeño Integral Municipal

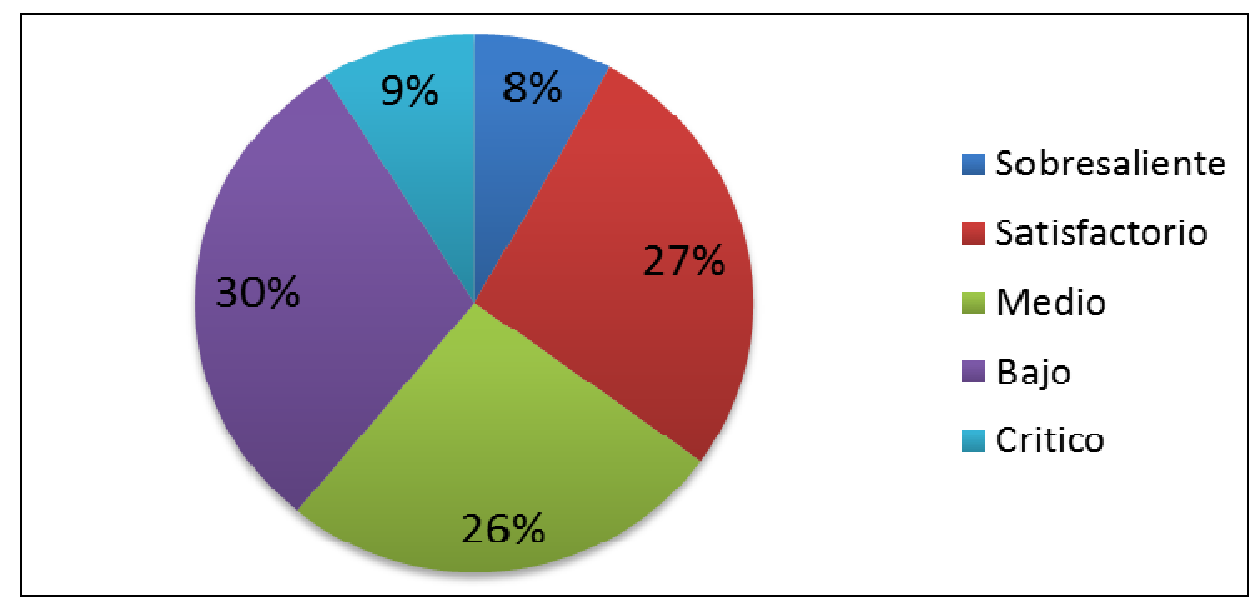


En la siguiente tabla se muestra los municipios que presentaron un mejor desempeño integral en la vigencia 2011.

Tabla 1 - Municipios de mejor desempeño integral, 2011

\begin{tabular}{lllllll}
\multicolumn{1}{c}{ Municipio } & Eficacia & Eficiencia & $\begin{array}{c}\text { Requisitos } \\
\text { legales }\end{array}$ & $\begin{array}{c}\text { Gestión } \\
\text { adtiva }\end{array}$ & $\begin{array}{c}\text { Índice } \\
\text { integral }\end{array}$ & $\begin{array}{c}\text { Ranking } \\
\text { nacional }\end{array}$ \\
\hline Palmira (Valle Del Cauca) & 93,2 & 91,4 & 97,4 & 87,0 & 92,3 & 1 \\
\hline Tuluá (Valle Del Cauca) & 99,9 & 75,3 & 99,0 & 86,6 & 90,2 & 2 \\
\hline Popayán (Cauca) & 86,9 & 90,1 & 98,4 & 85,4 & 90,2 & 3 \\
\hline Zipaquirá (Cundinamarca) & 97,9 & 78,5 & 97,0 & 86,7 & 90,0 & 4 \\
\hline Medelín (Antioquia) & 76,5 & 95,1 & 97,5 & 89,6 & 89,7 & 5 \\
\hline Sopó (Cundinamarca) & 94,5 & 68,6 & 99,4 & 91,6 & 88,5 & 6 \\
\hline Pitalito (Huila) & 96,1 & 80,5 & 92,7 & 84,5 & 88,5 & 7 \\
\hline Sogamoso (Boyacá) & 84,7 & 84,3 & 98,9 & 85,4 & 88,3 & 8 \\
\hline Chía (Cundinamarca) & 95,0 & 72,0 & 97,6 & 88,1 & 88,2 & 9 \\
\hline Neiva (Huila) & 99,3 & 84,7 & 83,6 & 84,4 & 88,0 & 10 \\
\hline Duitama (Boyacá) & 81,9 & 82,2 & 98,3 & 86,6 & 87,3 & 11 \\
\hline La Unión (Nariño) & 100,0 & 72,9 & 94,0 & 81,2 & 87,0 & 12 \\
\hline Ibagué (Tolima) & 79,7 & 84,2 & 97,1 & 84,9 & 86,5 & 13 \\
\hline Pereira (Risaralda) & 86,6 & 77,5 & 95,8 & 85,5 & 86,3 & 14 \\
\hline Garzón (Huila) & 90,5 & 76,3 & 96,6 & 81,8 & 86,3 & 15 \\
\hline Mosquera (Cundinamarca) & 84,6 & 76,0 & 96,8 & 87,5 & 86,2 & 16 \\
\hline La Vega (Cundinamarca) & 92,4 & 75,5 & 95,0 & 81,4 & 86,1 & 17 \\
\hline Sibaté (Cundinamarca) & 95,1 & 63,9 & 97,9 & 87,4 & 86,1 & 18 \\
\hline Chocontá (Cundinamarca) & 95,1 & 75,3 & 93,7 & 79,2 & 85,8 & 19 \\
\hline Madrid (Cundinamarca) & 91,9 & 63,0 & 96,7 & 91,5 & 85,8 & 20 \\
\hline Fuente: DNP(2011, p. 38$)$ & & & & & & 4 \\
\hline
\end{tabular}

Fuente: DNP (2011, p. 38).

Como se puede apreciar, ocho (8) municipios de Cundinamarca cercanos a la ciudad Capital presentan un desempeño integral satisfactorio, le siguen ciudades capitales de departamento, como Popayán, Medellín, Neiva, Ibagué, Pereira y luego municipios con influencia económica en los departamentos, como Palmira, 
Tuluá, Pitalito Sogamoso, Duitama, La Unión y Garzón. De manera que existe una correlación espacial entre los municipios cercanos al centro y el desempeño administrativo en el manejo de los recursos.

Gráfico 2 - Categoría de municipios de mejor desempeño municipal

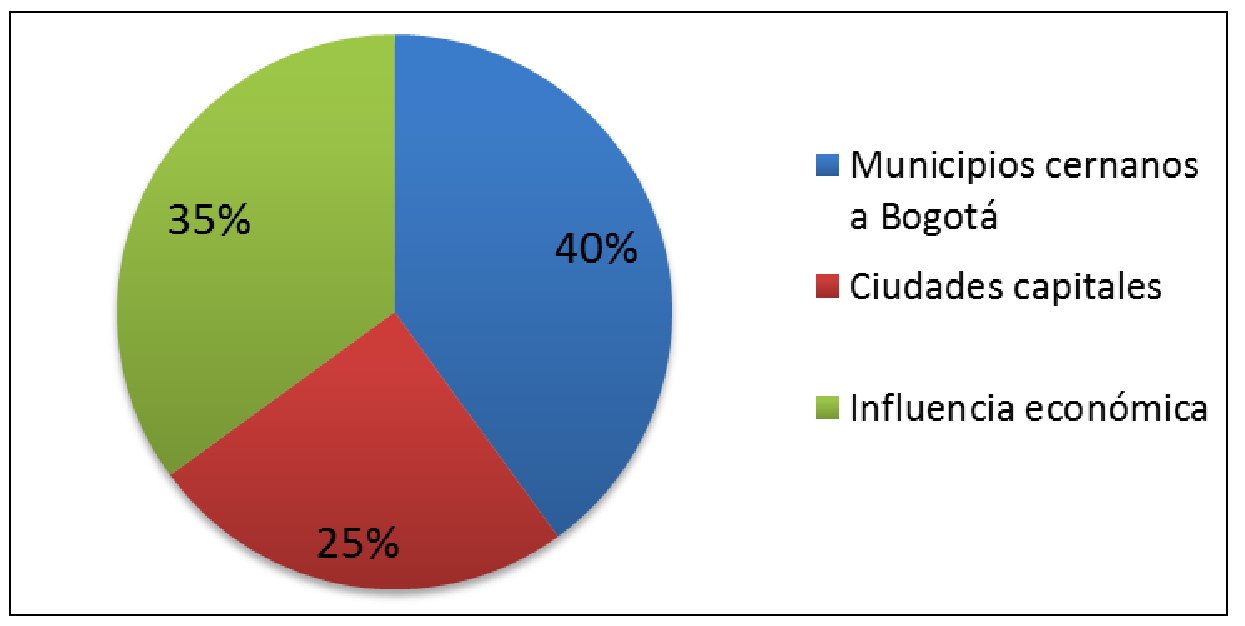

Por tanto, no es fortuito que la relación del desempeño fiscal y administrativo en el manejo de los recursos del Sistema General de Participaciones dependa de la distancia geográfica. En este sentido, la correlación espacial limita o potencia la capacidad operativa de las entidades, puesto que facilita o restringe la adopción de mejores prácticas mediante la retroalimentación de homólogos y mejora u obstaculiza los niveles de acompañamiento seguimiento y reporte de la información. De ahí que el modelo centralista genere distorsiones y merme de manera significativa el desempeño administrativo de las entidades territoriales.

Como bien lo demuestra el Departamento Nacional de Planeación, las razones que impiden mantener el equilibrio entre los ingresos y los gastos del Sistema General de Participaciones son:

- Inconvenientes en la programación y ejecución del presupuesto por parte de la administración.

- Sistemas de información presupuestales desactualizados.

- Baja capacidad institucional para articular la planeación con el proceso presupuestal territorial.

- Desconocimiento de la normatividad y de los lineamientos de los ministerios sectoriales.

- Falta de instrucciones claras por parte del Gobierno Nacional para la ejecución de los recursos del Sistema General de Participaciones. 
- Falta de asistencia técnica por parte de la secretaria de planeación departamental.

En consecuencia, el proceso de distribución de competencias en Colombia ha sido ambiguo por dos razones: la primera porque prevale el modelo nacióndepartamento-municipio, jugando el segundo un rol de mediador, tutor y evaluador de los municipios, convirtiéndose en un eslabón más del proceso de descentralización, lo que impide una real autonomía de los mismos, como bien lo afirma Velasco "la inercia del esquema mantiene la fragmentación del Estado en el territorio, lo cual significa que no se han habilitado mecanismos adecuados para que los diferentes órdenes administrativos actúen de manera coordinada en las jurisdicciones territoriales" (VASCO, 2004, p. 425); la segunda porque en aras de mantener la estabilidad financiera y evitar el colapso de las finanzas públicas, las entidades territoriales son sometidas a controles frecuentes por parte del gobierno nacional, debido a que prevalece la percepción de desconfianza institucional por parte del centro hacia la periferia mediante la estandarización de los procesos presupuestales, de manera que la periodicidad de los diagnósticos municipales para evaluar y mejorar la asignación y gestión de los recursos de las entidades territoriales puede ayudar a comprender el comportamiento administrativo, pero no garantiza una mejor gestión y una óptima descentralización territorial.

\section{Conclusión}

Si se tiene en cuenta los intereses políticos y económicos que sucumben en la ejecución de los recursos públicos en los diferentes niveles administrativos, es evidente que la voluntad de efectuar reformas sustanciales que conduzcan a una mayor autonomía territorial, esta medida como bien lo explica Vasco (2004, p. 425) por "la intermediación política de recursos presupuestales que tiene su propia estructura, su propia lógica y sus propias instituciones. La red que conforma desde las empresas electorales, que atraviesa los diferente órdenes administrativas del Estado, tiene poco interés en que se produzca reformas de fondo que alteren sus condiciones de operación. Parcelas significativas del presupuesto nacional y los diferentes fondos son objeto de transacciones", dicha intermediación política no se vislumbran tan fácilmente en el panorama de la descentralización, pues sus fibras son imperceptibles, por tanto el alcance en la discusión del ordenamiento territorial sólo se ha orientado al tema de competencias, barniz que no ha permitido debatir el incómodo y álgido tema sobre el manejo estratégico de la estructura espacial del desarrollo nacional [concepto de Utria (1995)] que no es más que definir las relaciones de poder en el territorio.

Finalmente, como lo anotam Morelli; Santofimio (1991): "El tema del ordenamiento territorial en Colombia está atravesado por el tema de la autonomía 
regional y su incidencia en el gasto público”. De ahí que los proyectos de reforma de Organización Territorial sean tímidos y solo se enfocan al tema de competencias, no al álgido debate de la Reorganización Regional y con ello el tipo de organización administrativa.

\section{Bibliografía}

DNP. Departamento Nacional de Planeación. Evaluación del desempeño integral de los municipios. Bogotá, Colombia: DNP, 2011. 311p.

MORELLI, Sandra; SANTOFIMIO, Jaime Orlando. El centralismo en la Nueva Constitución Política colombiana. Bogotá, Colombia: Instituto de Estudios Constitucionales Carlos Restrepo Piedrahita, 1991. 76p. Temas de Derecho Público.

SENTENCIA C-600-A/95 Diciembre 11. Corte Constitucional. Magistrado Ponente doctor Alejandro Martínez Caballero.

SENTENCIA C-701/10. Corte Constitucional. Magistrado Ponente Dr. Luis Ernesto Vargas Silva.

UTRIA, Rebén Dário. Ordenamiento territorial: hacia un enfoque conceptual. Revista Academia Colombiana de Ciencias Económicas, n. 34, 1995.

VASCO, Mauricio. Organización y Administración del Territorio. In: RET (Red de Estudios de Espacio y Territorio). Dimensiones territoriales de la guerra y paz. Bogotá, Colombia: Universidad Nacional de Colombia, 2004.

Endereço para correspondência:

MaríaLuisa Monroy Merchán - ensumalucha@gmail.com

Carrera 78 A N $^{\circ} 41 \mathrm{G} 22$ Sur

Bogotá, DC, Colômbia 